Gut, 1986, 27, 528-533

\title{
Function of the anal sphincters after chronic radiation injury
}

\author{
J S VARMA, A N SMITH, AND A BUSUTTIL \\ From the University Department of Surgery/Urology, Wolfson Gastrointestinal Laboratory and Department \\ of Pathology, Western General Hospital, Edinburgh
}

SUMmaRY Anorectal manometry was done in 10 men with chronic radiation proctitis and symptoms of urgency, frequency, and occasional incontinence of faeces. They were compared with 10 asymptomatic age and sex-matched controls. The maximum resting anal canal pressure and the physiological sphincter length were significantly lower $(p<0.01)$ in the irradiated group. The rectosphincteric reflex was absent in one patient and showed abnormalities of recovery in four others, who had received radiotherapy. The squeeze pressure of the external sphincter was not significantly different. These results indicate that dysfunction of the internal anal sphincter may contribute to patients' anorectal symptoms after pelvic radiotherapy. Histological evidence suggests that damage to the myenteric plexus is mainly responsible. The manometric function of the external sphincter remains relatively unaffected.

Radiotherapy is being increasingly used for the treatment of malignancy arising in the pelvic viscera. ${ }^{1}$ Inevitably, the incidence of associated radiation injury to healthy surrounding tissue with its sequelae has increased, sometimes necessitating surgical intervention. ${ }^{2-4}$ The rectum is the commonest site of injury after pelvic irradiation; more than $70 \%$ of patients with radiation gastrointestinal injury have this site involved, sometimes in conjunction with other organs. ${ }^{45}$ The fixed anatomical position of the rectum in the pelvis makes it more susceptible to the injurious effects of radiation compared with the more 'mobile' organs such as the small bowel.

A very common symptom of radiation anorectal injury is loose bowel motions with faecal incontinence, often chronic in nature. ${ }^{4}$ Some of this symptomatology may be explainable by the accompanying proctitis and changes in rectal physiology. ${ }^{67}$ It is conceivable that the continence function of the pelvic floor is also compromised as a result of the radiation injury, thus aggravating the severity of the faecal incontinence.

We have manometrically evaluated the function of the internal and external anal sphincters in patients with symptomatic chronic radiation rectal

Address for correspondence: Mr A N Smith. FRCS. University Department of Surgery/Urology. Western General Hospital. Edinburgh EH4 2XU.

Received for publication 16 August 1985 injury and compared it with a matched control group of asymptomatic subjects.

\section{Methods}

PATIENTS

Approval for this investigation was obtained from the ethical committee of the North Lothian District, Lothian Health Board, Edinburgh, Scotland, on 16 June 1983. Informed consent was obtained from all the subjects participating in the study. The symptomatic irradiated group comprised 10 men (age range 63-80 years, mean 74 years) who received radiotherapy for prostatic carcinoma and all had subsequently developed the symptoms of faecal incontinence, increased frequency, urgency and occasional loose bowel motions. Identical small field external beam radiotherapy (5000 Centigrays in 20 treatments over four weeks) had been given to this group of men from 2 to 5.5 years before the study (mean 3.5 years). The control group consisted of 10 age-matched male hospital patients who had been admitted for minor surgery not involving the gastrointestinal tract and who had no anorectal symptoms.

\section{MANOMETRY}

All subjects were requested to empty their bowel before the pressure studies. Anorectal manometry was done with the patient in the left lateral position. A water filled system consisting of microballoon 
(internal diameter $4 \mathrm{~mm}$ HSC4, Precision Dippings Ltd, Bristol, UK) mounted onto a 6 FG ureteric catheter and connected via an external transducer (4-442, Bell \& Howell Ltd, UK) to a chart recorder (Devices Ltd, UK) was used to measure anal canal pressure. The system was precalibrated and the balloon introduced into the rectum $6 \mathrm{~cm}$ from the anal verge and rectal pressure measured. The balloon was then withdrawn in steps of $0.5 \mathrm{~cm}$ and the resting pressure of each 'station' measured until a stable value was obtained. The subject was also asked to contract the external sphincter and the maximum voluntary contraction pressure recorded. The 'squeeze' pressure or the external sphincter contribution to this pressure was calculated as the difference between the maximum voluntary contraction pressure and maximum resting pressure. The rectosphincteric reflex was elicited by placing the microballoon at the site of maximum resting pressure and quickly distending the rectum by inflating a $2 \times 1 \mathrm{~cm}$ soft rubber balloon ( $\mathrm{HSC1}$, Precision Dippings Ltd, Bristol, UK) with $50 \mathrm{ml}$ air. The rectal balloon was placed at $10 \mathrm{~cm}$ from the anal verge. The decrease in the resting anal canal pressure on rectal distension was recorded as the amplitude of the rectosphincteric reflex.

All the data were analysed by means of the Wilcoxon's test for pair differences.

HISTOPATHOLOGICAL MATERIAL

Histological material was obtained from eight other patients who had undergone excisional surgery for complications of radiation rectal injury. Six of these patients had been treated for bladder cancer and two for prostatic cancer (mean 2.2 years before surgery). The total radiation dosage that these patients had received ( 3000 to 5000 Centigrays) was similar to that used in the study group of symptomatic but unoperated patients (5000 Centigrays). Formalin-treated tissue from the lower rectum was examined by conventional haematoxylin and eosin staining and light microscopy after paraffin embedding. Special stains were not used. At least three sections were examined from each patient.

\section{Results}

MANOMETRY AND SYMPTOMS

Figure 1 shows a comparison of the maximum resting anal canal pressures between the two groups. There is a significant reduction in this pressure in the radiation group $(p<0 \cdot 01)$. Figure 2 compares the length of the manometrically determined highpressure zone in the two groups as measured with the station pull through technique. This is also significantly reduced in the radiation group

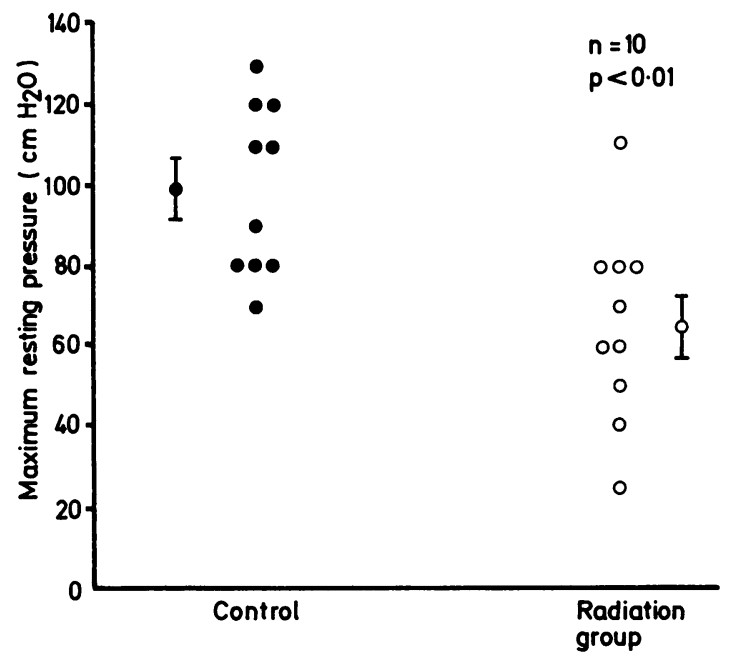

Fig. 1 Maximum resting pressure in the anal canal shown with mean $\pm S E M . n=10, p<0.01$ (Wilcoxon's test).

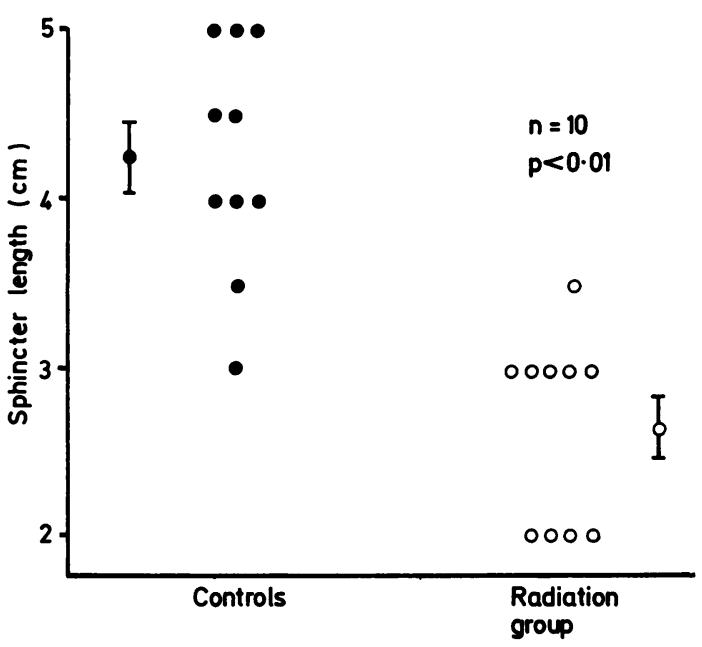

Fig. 2 Functional resting sphincter length in the anal canal shown with mean $\pm S E M . n=10, p<0.01$ (Wilcoxon's test).

$(p<0 \cdot 01)$. The Table shows the values for the other parameters measured and their statistical significance. The presence and recovery of the rectosphincteric reflex was affected by radiation. The amplitude was significantly reduced after radiation and in one patient the reflex was absent. All control subjects showed restoration of the maximum resting pressure to baseline levels within 30 seconds on inflation of the rectal balloon and immediately on deflation of the balloon. In contrast, four patients in the radiation group showed no recovery of this 
Table Comparison of the five sphincter parameters in the two groups

\begin{tabular}{|c|c|c|c|}
\hline Parameter & $\begin{array}{l}\text { Control } \\
\text { group } \\
(n=I 0)\end{array}$ & $\begin{array}{l}\text { Radiation } \\
\text { group } \\
(n=10)\end{array}$ & $\begin{array}{l}\text { Significance } \\
\text { (Wilcoxon's } \\
\text { signed rank } \\
\text { sum test) }\end{array}$ \\
\hline Maximum resting & 99 & 66 & \\
\hline pressure & \pm & \pm & $\mathrm{p}<0) \cdot() 1$ \\
\hline$\left(\mathrm{cm} . \mathrm{H}_{2} \mathrm{O}\right.$, mean \pm SEM $)$ & $6 \cdot 7$ & $7 \cdot 6$ & \\
\hline $\begin{array}{l}\text { Functional sphincter } \\
\text { length }\end{array}$ & $\begin{array}{l}4 \cdot 25 \\
\pm\end{array}$ & $\begin{array}{l}2 \cdot 65 \\
\pm\end{array}$ & $\mathrm{p}<0) \cdot(01$ \\
\hline$\left(\mathrm{cm} . \mathrm{H}_{2} \mathrm{O}\right.$. mean $\left.\pm \mathrm{SEM}\right)$ & 0.2 & $\overline{(0 \cdot 2}$ & \\
\hline $\begin{array}{l}\text { Amplitude of } \\
\text { rectosphincteric }\end{array}$ & 46 & 25 & \\
\hline reflex & \pm & \pm & $\mathrm{p}<0) \cdot(12$ \\
\hline$\left(\mathrm{cm} . \mathrm{H}_{2} \mathrm{O}\right.$, mean $\left.\pm \mathrm{SEM}\right)$ & $2 \cdot 7$ & $4 \cdot 8$ & \\
\hline $\begin{array}{l}\text { Maximum voluntary } \\
\text { contraction pressure }\end{array}$ & $\begin{array}{l}219 \\
\pm \\
10.5\end{array}$ & $\begin{array}{l}151 \\
\pm \\
16 \cdot 9\end{array}$ & $\mathrm{p}<0.0 .05$ \\
\hline $\begin{array}{l}\text { Maximum squecze } \\
\text { pressure } \\
\left(\mathrm{cm} . \mathrm{H}_{2} \mathrm{O}, \text { mean } \pm \mathrm{SEM}\right)\end{array}$ & $\begin{array}{l}120 \\
\pm \\
10 \cdot 9\end{array}$ & $\begin{array}{l}86 \\
\pm \\
27 \cdot()\end{array}$ & $\begin{array}{l}p>0.5 \\
(N S)\end{array}$ \\
\hline
\end{tabular}

reflex as long as the balloon remained inflated, and time to recovery of resting pressure was prolonged to more than 60 seconds on deflation of the balloon.
The remaining five patients showed normal recovery of the reflex. Maximum voluntary contraction pressure was reduced in the radiated group but this is probably attributable to the reduced maximum resting pressure because no difference in the 'squeeze' pressure - that is, maximum voluntary contraction pressure minus maximum resting pressure, could be demonstrated $(\mathrm{p}>0.05)$. All the patients had identical symptoms of urgency and frequency of defaecation with occasional faecal incontinence.

\section{HISTOPATHOLOGY}

Microscopic examination of the sections taken from all the eight resected specimens showed identical histopathological changes. Figures 3,4 , and 5 are sections taken from the lower rectums of patients who had undergone anterior resection of the rectum with coloanal sleeve anastomosis for severe radiation injury. They show the histopathological effects of irradiation on the neuronal plexuses and smooth muscle. There is hypertrophy of the muscle of both the muscularis mucosae and muscularis propria with some enlargement of the myocytic nuclei (Figs 3 and 4). In the submucosal nerve plexus (Meissner's)

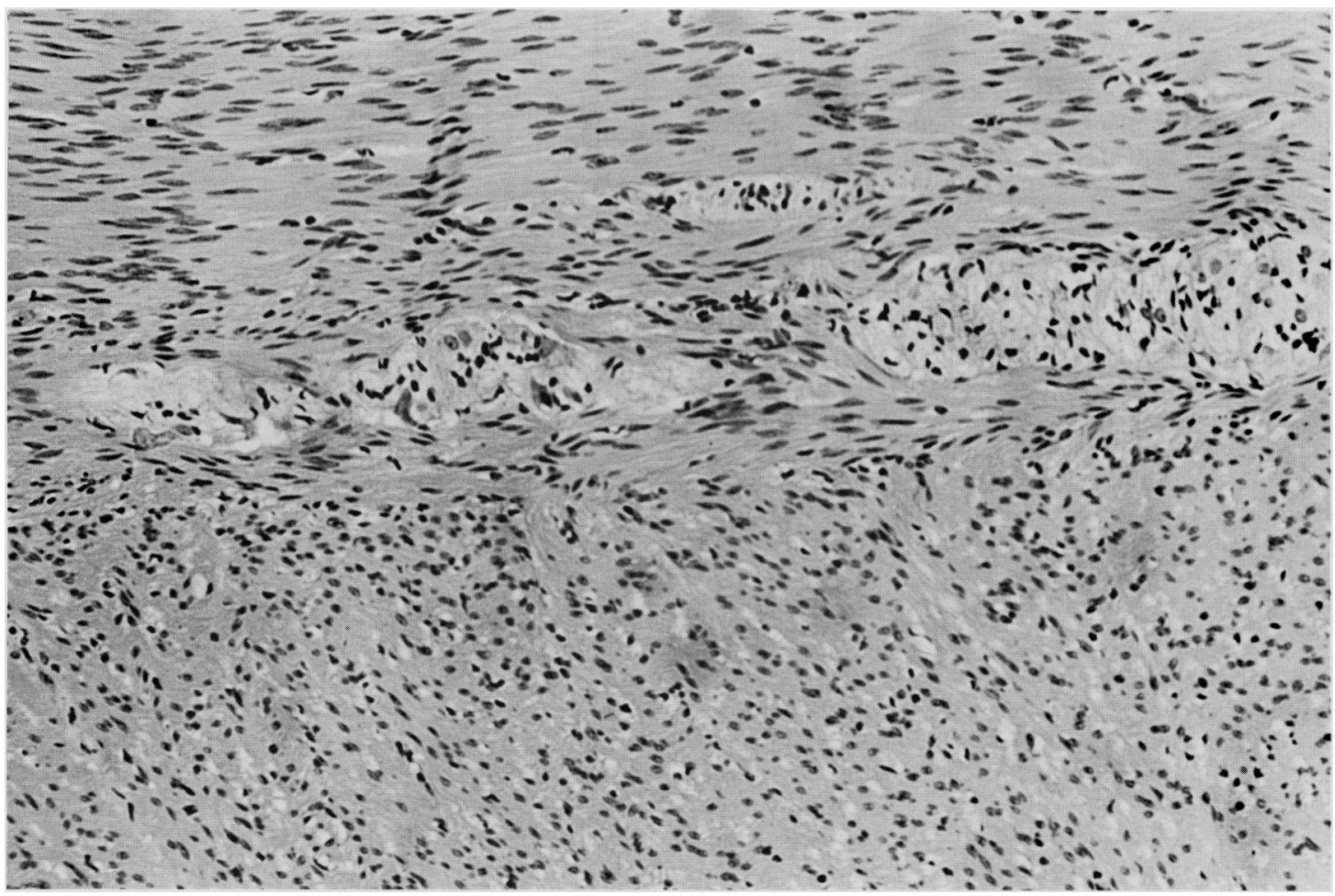

Fig. 3 Lower rectum. Hypertrophy of the muscularis layers and prominence of Auerbach's plexus (H\&E $\times 40$ orig. mag.). 


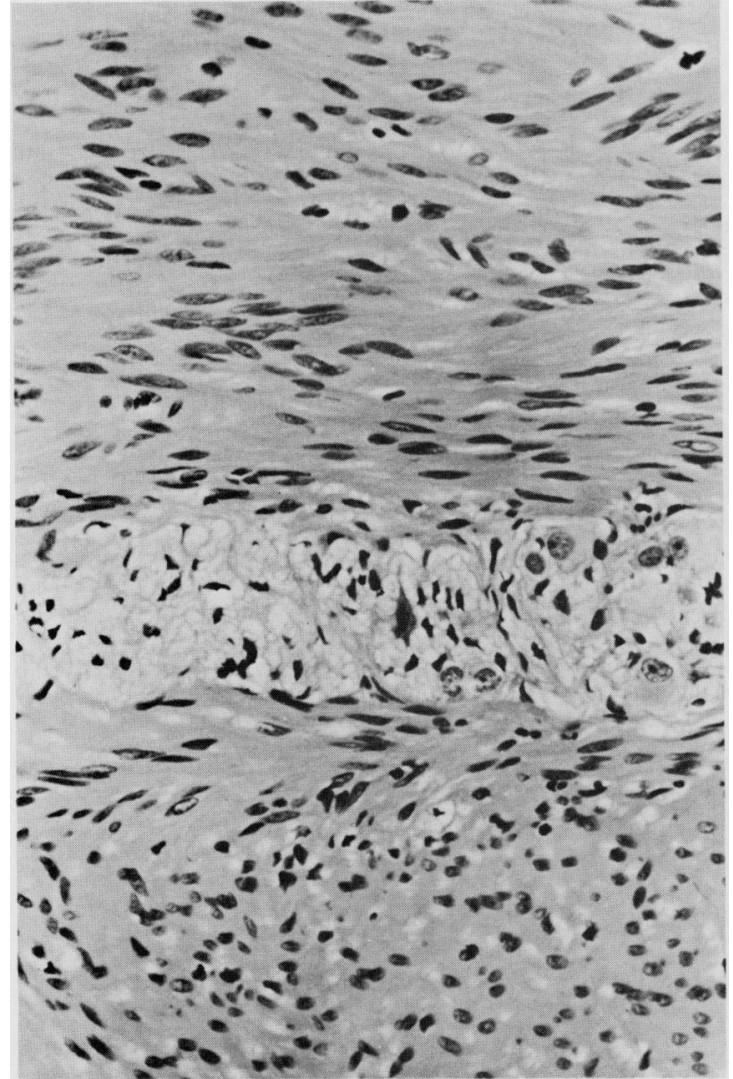

Fig. 4 Auerbach's plexus. Vacuolation of proliferated nerve sheaths and paucity of ganglion cells $(H \& E \times 400$ orig. mag.).

ganglion cells are sparse but hypertrophy of the nerve fibres is not present. The few ganglion cells are degenerate and their nuclei pyknotic. In the muscular plexus (Auerbach's) there is marked hypertrophy of the nerve fibres with vacuolation of the nerve sheaths giving the plexus a laciform pattern (Figs 3 and 4). The ganglion cells are diminished in number and show cytoplasmic vacuolation and degranulation (Fig. 5). Their nuclei are eccentrically placed. The chromatin pattern is altered with increase in density, loss of outline of the nuclear membrane and diminution of nucleolar prominence.

\section{Discussion}

Urgency, increased frequency of defaecation and incontinence of faeces are common symptoms in patients with chronic radiation anorectal injury. ${ }^{4}$ There is evidence that reduction in rectal compli- ance and volume is partly responsible for these symptoms. ${ }^{67}$ The pelvic floor - in particular the anal canal and sphincters - is also susceptible to the effects of radiation directed at the primary pelvic pathology. Damage to the sphincteric mechanisms may therefore further compromise continence. The purpose of this study was to determine whether anal sphincter function is affected in patients with the symptoms of chronic radiation rectal injury. All the irradiated patients had identical symptoms of faecal incontinence with urgency and frequency of defaecation. Male patients were chosen for the study to eliminate the effects of parturition ${ }^{8}$ and chronic straining at stool ${ }^{9}$ predominantly found in women with resultant effects on sphincter function. None of the patients had anorectal symptoms before radiotherapy. Digital rectal examination of the prostate had been carried out only at six monthly intervals after radiotherapy and was therefore not presumed to have had any adverse effects on anal sphincter function. Although the histological preparations were taken from different patients to those studied manometrically, the total therapeutic dosage of pelvic irradiation delivered to the two groups and the time since radiation was identical.

The internal anal sphincter is responsible for up to $85 \%$ of the maximum resting pressure in the anal canal $^{10}$ and therefore also for the length of its manometric high pressure zone. The significant reduction in the maximum resting pressure and physiological sphincter length in the irradiated group suggests dysfunction of this muscle. Relaxation of the internal anal sphincter on distension of the rectum is a smooth muscle reflex partly mediated via the myenteric plexus ${ }^{11}$ although receptors in the pelvic floor may share in this. ${ }^{12}$ The abnormalities in the elicitation, amplitude, and recovery of this reflex after pelvic radiotherapy point to a possible functional abnormality of the autonomic ganglion cells or axons constituting this neuronal network. The reduction in the amplitude of the rectosphincteric reflex in the irradiated group is partly because of the lower resting anal canal pressures but can also be influenced by other variables - for example, the radius of the rectal lumen and compressibility of the air filling the rectal balloon. Nevertheless, it has been used as an index of internal sphincter function by other workers ${ }^{13-16}$ and complements the results obtained from measurement of the other parameters in this study. Furthermore, there is some evidence that the presence and amplitude of the rectosphincteric reflex is inversely related to the compliance and accommodation properties of the rectum. ${ }^{13}$ 15-17 The observation that this reflex is reduced after radiation injury - that is, in the presence of severe 


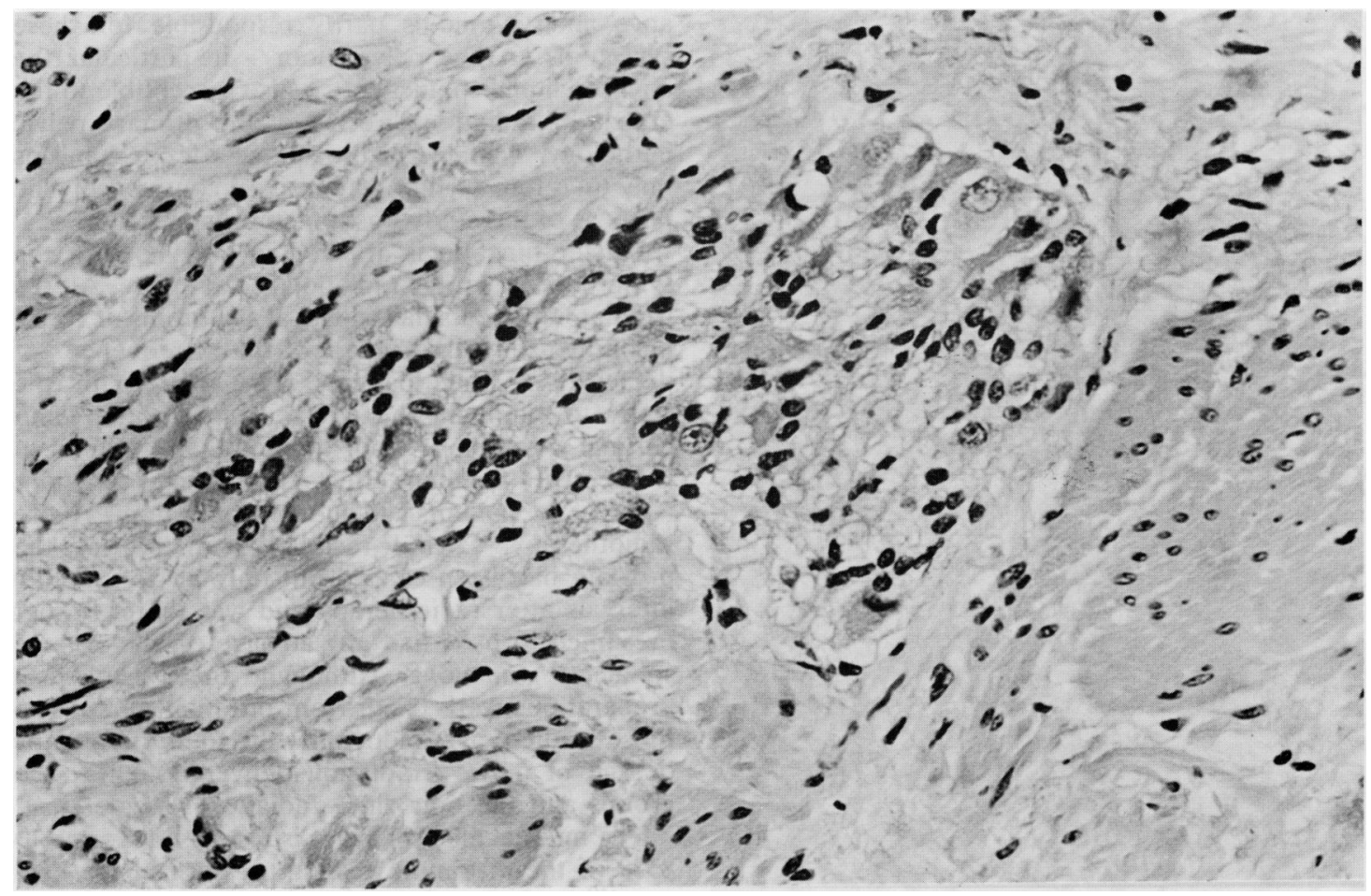

Fig. 5 Auerbach's plexus. Ganglion cells showing vacuolation of the cytoplasm and degeneration and pyknosis of their nuclei (H\&E $\times 400$ orig. mag.).

reduction in rectal compliance, is therefore good evidence of internal anal sphincter malfunction in this disorder. It is relevant that similar abnormalities of the rectosphincteric reflex may be seen in Hirschprung's disease where the significant pathology is an absence of the ganglion cells ${ }^{11}$ and in other forms of neuronal intestinal dysplasia. ${ }^{18} 19$ The hypertrophy of the smooth muscle seen in the histological preparations is further evidence of damage to the myenteric plexus as there is some evidence that denervated smooth muscle hypertrophies. $^{20}$

The function of the striated external sphincter as evaluated manometrically appears relatively less prone to the effects of pelvic irradiation. This is perhaps not surprising as somatic nerve axons and muscle are considered relatively resistant to radiation $^{21}$ with resultant 'sparing' of the manometric function of this sphincter. It remains possible, however, that late effects occur with microvascular involvement. ${ }^{21}$ Modern electrophysiological methods $^{22-24}$ may be able to provide further information on the effects of radiation on the function of the striated musculature of the pelvic floor. With higher doses of local irradiation such as that used for the treatment of cervical cancer, dysfunction of the external sphincter may become more apparent.

This study shows physiological dysfunction of the internal anal sphincter in symptomatic radiation anorectal injury. This may contribute to and therefore aggravate symptoms caused by abnormalities of rectal function. ${ }^{7}$ The manometric and histopathological evidence suggests that radiation damage to the relatively radiosensitive myenteric plexus is an important factor in the pathophysiology of this disorder, although a degree of direct damage to smooth muscle may also occur.

Awareness of the pathophysiological effects of radiation on pelvic floor function may lead radiation oncologists to study the feasibility of less injurious techniques and gastroenterologists to search for better therapeutic measures.

J S V was supported by a Wellcome Trust Research grant no $1219614 \mathrm{~L}$. We are most grateful to Professor G D Chisholm and Mr L L Beynon for enabling us to study patients under their care. 


\section{References}

1 MRC Working Party. A trial of preoperative radiotherapy in the management of operable rectal cancer. Br J Surg 1982; 69: 513-9.

2 Morganstern L, Thompson R, Friedman NB, The modern enigma of radiation enteropathy. Am J Surg 1977; 134: 166-72.

3 Schmitt EH, Symmonds RE. Surgical treatment of radiation-induced injuries of the intestine. Surg Gynecol Obstet 1981; 153: 896-900.

4 Hatcher PA, Thomson H, Ludgate S, Small WP, Smith AN. Surgical aspects of intestinal injury due to pelvic radiotherapy. Ann Surg 1985; 201: 470-5.

5 Anseline PF, Lavery IC, Fazio VW, Jagelman DG, Weakley FL. Radiation injury of the rectum. Ann Surg 1981; 194: 716-24.

6 Varma JS, Smith AN. Rectal function after pelvic irradiation. Gut 1984; 25: 554.

7 Varma JS, Smith AN, Busuttil A. Correlation of clinical and manometric abnormalities of rectal function following chronic radiation injury. Br J Surg 1985 ; 72: 875-78.

8 Snooks SJ, Setchell M, Swash M, Henry MM. Injury to innervation of pelvic floor sphincter musculature in childbirth. Lancet 1984; 2: 546-50.

9 Kiff ES, Barnes PRH, Swash M. Evidence of pudendal neuropathy in patients with perineal descent and chronic staining at stool. Gut 1984; 11: 1279-84.

10 Dickinson VA. Progress report. Maintenance of anal continence: a review of pelvic floor physiology. Gut 1978; 19: 1163-74.

11 Nixon NH. Hirschprung's disease. Arch Dis Childh 1964 39: 109-15.

12 Lane RHS, Parks AG. Function of the anal sphincters following coloanal anastomosis. Br J Surg 1977; 64: 596-9.
13 Iwai N, Ogita S, Kida M, Nishioka B, Fujita Y, Majima $\mathrm{S}$. A manometric assessment of anorectal pressures and its significance in the diagnosis of Hirschprung's disease and idiopathic megacolon. Jpn J Surg 1979; 9: 234-40.

14 Taylor I, Hammond P, Darby C. An assessment of anorectal motility in the management of adult megacolon. Br J Surg 1980; 67: 754-6.

15 Lanfranchi GA, Bazzochi G, Brignola C, Campieri M, Labo G. Different patterns of intestinal transit time and anorectal motility in painful and painless chronic constipation. Gut 1984; 25: 1352-7.

16 Callaghan RH, Nixon HH. Megarectum: physiological observations. Arch Dis Childh 1964; 39: 153-7.

17 Arhan P, Faverdin C, Persoz B, Devroede G, Dubois F, Dornic F, Pellerin D. Relationship between viscoelastic properties of the rectum and anal pressure in man. J Appl Physiol 1976; 41: 677-82.

18 Scharli AF, Meier-Luge W. Localised and disseminated forms of neuronal intestinal dysplasia mimicking Hirschprung's disease. J Pediatr Surg 1981; 16: 164-70.

19 Smith B. Disorders of the myenteric plexus. Gut 1970; 11: $271-4$.

20 Alvarez WC. A simple explanation for cardiospasm in Hirschprung's disease. Gastroenterology 1949; 13: 422-9.

21 Rubin P, Casarett GW. Clinical radiation pathology. Vol II. London: Saunders, 1968.

22 Neill ME, Swash M. Increased motor unit fibre density in the external anal sphincter muscle in anorectal incontinence: a single fibre EMG study. $J$ Neurol Neurosurg Psychiatry 1980; 43: 343-7.

23 Buchtal F, Pinelli P. Action potentials in muscular atrophy of neurogenic origin. Neurology (Minneap) 1953; 3: 591-603.

24 Smith AN, Varma JS. The latency of the pudendoanal reflex in man. J Physiol 1984; 360: 49P. 